Pulished in: Space, Time and The Limits of Human Understanding

Shyam Wuppuluri, Giancarlo Ghirardi (Editors), Cham: Springer 2017

Time and Suffering - False Metaphors, (De-)synchronous Times, and Internal

Dynamics

Norman Sieroka

Pages 372-380

DOI: $10.1007 / 978-3-319-44418-5$

Current affiliation of author (March 2021):

Theoretische Philosophie,

Universität Bremen

www.uni-bremen.de/theophil/sieroka

\begin{abstract}
:
At times, people feel something which they would describe as "time pressure". But is time really a substance which could put pressure on us? I shall argue that it is not and that indeed a philosophical revisionism is sought for in this context; namely the avoidance of the permanent use of such false physical and economic metaphors like "time pressure", "time costs", "loss of time". Having said that, the real phenomenon underlying this metaphorical talk is a discrepancy or dissonance between different times scales: the individual time scale of a person as structured by her intentions, aims, and goals; and an objective time scale or intersubjective time scale as structured by (natural or social) events of the world around her. I will argue that also the so-named "fear of death" - that is, the suffering resulting from the worry about one's finitude can be classified as a special type of such a dissonance; namely as an irreversible dissonance or desynchronization based on the overall stoppage of one's individual time. This stoppage, in turn, will be characterised as the termination point of the ever new and tensed division or divergence between what is experienced as happening now and as being just past. Towards the end of the paper I will come back to the question of a philosophical revisionism - that is, to the cases where discrepancies or dissonances between individual time and intersubjective time do allow for a "re-synchronization" and, thus, for an avoidance of suffering.
\end{abstract}

\title{
Time and suffering
}

\section{False Metaphors, (De-)synchronous Times, and Internal Dynamics}

\section{Norman Sieroka}

\section{Introduction: Sufferings and Time Scales}

Time can make one suffer. On a general level, one might realise one's own finitude and one might suffer from the fact that there are good inductive reasons to suppose that the world around will carry on after one's death. On a more everyday level, one may suffer from what is often described as "stress" and "time pressure": myriads of appointments, 
deadlines, commitments keeping one busy to an unhealthy extent. In what follows I will analyse the origins of these two kinds of individual suffering. (I use the term "individual suffering" because it is related to personal life-worldly limitations and has to be distinguished from a notion of formal suffering, as related to the human capacity of receptiveness quite generally, and from a notion of social suffering, as resulting from shared traumatic experiences of a whole community; cf. Renault 2010, Sieroka 2016.)

Apart from analysing the origins of these time-induced sufferings, I will attempt to answer the question whether or to what extent they can be avoided or overcome - that is, I will look at the possibilities and limits of a philosophical revisionism regarding our awareness and understanding of time.

In order to explicate these phenomena in an adequate fashion, it is helpful to first distinguish between different time scales. Generally speaking, time is a fundamental dimension of the world we live in. Given that there are different ways in which we encounter this world, there are also different ways in which one may ascribe a temporal order to (the objects of) these encounters (cf. Sieroka 2009 and 2015). One obvious way to give a temporal order to events or things is by means of clocks - that is, by ordering them in relation to periodical physical processes and, thus, by what one might call physical or "objective” time. Not determined by clocks, but given by the way we experience the enduring presence and absence of things, is a different time scale, namely "individual time". This second time scale might also be described as "time as perceived" (by an individual subject) and is to be distinguished from a third scale which might be called "intersubjective" time and which governs our daily social life - that is, our interaction with others.

All three time scales - physical, individual, and intersubjective - are experienced as real and usually we are not aware of any dissonances or discrepancies between them. In fact, the true core of expressions such as "time pressure" is related to the (unusual or pathological) case of experiencing such a discrepancy or dissonance. However, before explicating this "true core", let me start by explaining why expressions such as "time pressure" and "time costs" are indeed misleading and might themselves intensify a potential suffering.

\section{Overcoming False Metaphors Regarding Time}

As already mentioned, time is a fundamental dimension of the world, but time is not a substance. We experience ourselves as living in time (both physically as well as mentally), but time, especially physical time, is nothing one could collect, gather or accumulate. Even though this point might seem trivial, it is important to emphasise that time is not a material or economic resource. It is important because a lot of contemporary talk about time works as if time was such a resource and because a lot of suffering is related to taking these false metaphors seriously.

Given that time is not a material substance, time cannot put pressure on something or someone. Similarly, there can be no "lack of time" in any literal sense. Every day lasts twenty-four hours and no day has a leak through which some of these 
twenty-four hours might seep away. By the same token, time is not like money. To speak of "time savings" and "time costs" is to employ bad metaphors, for there is no way in which one might, for instance, salt away a couple of minutes on Tuesday to then withdraw them on Saturday.

This is not to deny that there are real phenomena related to the use of expressions like "time pressure" and "time costs". But these real phenomena are related to the durations and relative arrangements of actions and events (and I will come back to this in more detail below). At this point I merely want to emphasise that this talk about time itself being a material and economic substance or resource is misleading in a systematic fashion. It suggests that there are issues with time itself whereas the issues are really about us and about our organisation of events in time. Today as well as yesterday and tomorrow we have "all the time in the world", as it were - that is, twentyfour hours a day. No more, no less. But as soon as one starts to think that time works like money, one might start to shove more and more appointments into one's datebook because this seems similar to being rich and important. However, whereas a wallet might indeed stretch as I become richer and put more and more coins and banknotes into it, a day does not do anything similar ... and instead of becoming rich I merely start being stressed out.

This example might suffice to illustrate how such economic metaphors can have a negative influence on human life by decreasing one's overall well-being. Accordingly, one would do better by avoiding or revising the use of such metaphors. This might be a first and indeed important goal of philosophical inquiries about time: to reveal bad metaphors and to encourage and help overcoming them. Of course, it is by no means a new idea that a central aim of philosophy is to do revisionary work on metaphors - this has been argued for in various other contexts by, for instance, Nietzsche (1982) and, more recently, by Lakoff and Johnson (1980).

This kind of revisionism, however, can only be a first step. Even if one successfully overcomes all material and economic metaphors regarding time, one might still feel some kind of temporal disquietness or urgency. So let me explicate this urgency more precisely and relate it more specifically to the different times scales mentioned above.

\section{Desynchronized Time Scales}

The (temporal) relations on the individual time scale are fundamentally tensed. We experience things to happen now, we remember certain events to have happened in the past, and we anticipate certain things to occur in the future. That is, the temporal order of our immediate encounter with the world is ordered in tensed terms of "being present”, "being (more or less) past”, or "being (more or less) future”. In contrast, objective or physical time is usually described in tenseless terms. That is, the fundamental ordering relation here is that of "being earlier" or "being later".

There is a long and ongoing debate about which kind of temporal ordering is more fundamental on a metaphysical level: the tensed or the tenseless one? This debate 
was triggered largely by McTaggart (1908) and recent advocates of tenseless and tensed views include Mellor (1998) and Bourne (2007), respectively. In any case, what is important in the present context is the fact that even those philosophers who defend a tenseless view on the metaphysical level admit that our experiences come in a tensed order and that there is something like the inescapable presence of experience (see, e.g., Mellor 1998: 58-62).

When it comes to everyday life, actually both kinds of temporal orderings, tensed and tenseless, are important. Tenseless orderings are particularly important for making appointments with friends, authorities, medical practitioners, etc. Calling my dentist's office, I will arrange for an appointment on April $25^{\text {th }}$ at $8 \mathrm{am}$, say. And I will talk about this appointment with the receptionist in exactly those tenseless terms: "April $25^{\text {th }}$ at 8am". Our conversation will not include tensed classifications about the appointment - that is, there will be no phrasings such as "in thirty-seven days, twentyone hours and sixteen minutes from now” ... and one obvious reason for avoiding such tensed talk is that we would have to permanently update this talk every passing minute. In contrast, tensed orderings are particularly important in situations where an immediate action is in demand. To take a simple example: if I intend to cross the street it is extremely important for me to realise that the black SUV is approaching me from the left right now ... whereas, at that very moment, the tenseless classification of the looming accident (i.e. whether it is $3: 13 \mathrm{pm}$ or $3: 16 \mathrm{pm}$, say) appears irrelevant. Similarly, also the (tensed) difference between being past and being future is relevant in everyday life and makes a huge difference regarding suffering and overall well-being. Usually we prefer good things to happen in the future rather than the past, whereas the opposite holds true for adverse events. Parfit (1984: 158-162) calls this the "bias towards the future" and an, again simple, example might be my painful visit at the dentist which, if I had the choice, I would prefer to have already happened in the past instead of being the first thing to happen tomorrow morning.

To sum up and to relate things to the terminology from above: tensed orderings are fundamental to what I have called the individual time scale, whereas tenseless ordering relations provide the basis for what I have called the intersubjective time scale and the physical (objective) time scale. Note that this is not to claim that intersubjective time and physical time are the same (cf. Sieroka 2015: 212-226). However, at this point nothing much hinges on this difference. In fact, the "true core" of those aforementioned bad metaphors such as "time pressure" can be uncovered independently from that distinction.

What really happens in cases where people claim to be under (temporal) pressure is a desynchronization between one's individual time and the time of one's environment; whereby "environment" might refer either to the social reality, and hence to intersubjective time, or to nature, and hence to physical time. Due to an upcoming storm-front a fisherman might have to hurry up in order to reach the coast "in good time". However, it is not that physical time would put pressure on him. The concern is about the rhythm of his individual actions in relation to physical time. And even if there 
is no upcoming storm: the fisherman still needs to be synchronized with certain natural rhythms such as given by the cycle of day and night or maybe the tides.

Structurally, the same holds true for the relation between individual time and intersubjective time. There is no pressure originating from intersubjective time itself. Again, the problems of an alleged "time pressure" arise from desynchronization (see Blumenberg 1986). More precisely, the desynchronization is a "running after" of the individual time: I feel "under pressure" because the others around me are all ahead of me. As a simple example: having lunch with my colleagues and realizing that I am the only one who hasn't finished his pasta yet makes me feel uncomfortable and I start to wolf down my pasta because I know that everyone would like to return to work as soon as possible. This feeling might indeed be described as a kind of social pressure. However, just to reemphasise this point, this feeling results from a discrepancy or mismatch between my expectations and actions as compared to my colleagues' expectations and actions - it is by no means time itself (neither individual nor intersubjective time) which is pushing me.

Of course, the pasta example is "harmless" in the sense that one would hardly speak of a case of (severe) suffering. However, things come in degree here and the general mechanism is always the same. A repeated or even continuous running behind of my individual time, as compared to intersubjective time, makes me feel that I am always too late, that all the important things happen ahead of me, and all the important decisions are made before I made up my mind. It is for this reason that scholars from philosophy and psychopathology identify this (pathological) case of desynchronization between individual time and intersubjective time with depression (see Theunissen 1991, Fuchs 2001).

In turn, the pathological occurrence of the opposed desynchronization - that is, the case in which one's individual time is permanently ahead of the intersubjective time - has been identified with mania (cf. again [7, 24]) So mania is the pathological case of what might start out as a kind of boredom. To use the above example again: this time I am faster at lunch than my colleagues are and now I am bored because I have to wait for them to finish their pasta. Next, my boredom might change to impatience and then I might become fussy, calling the waiter, carelessly flicking through the newspaper from the next table, doing a quick call on my cell phone, starting to agitate my colleagues, counting the cash in my wallet, calling the waiter again, getting my jacket, doing another quick phone call, etc.

It is not my point whether this characterisation in terms of doing a lot of unrelated short-term actions is the correct way to describe the borderline between agitation and mania (for more details cf. Binswanger 1960, Fuchs 2013, Sieroka 2016). My aim is simply to illustrate the fact that both types of desynchronization between individual time and intersubjective time can lead to suffering.

\section{Re-synchronization and Escapism}


If the explication from Section 3 is correct, then it is obvious what a revisionism has to aim for in order to escape from boredom, impatience, and agitation on the one hand and stress, grief, and depressiveness on the other: namely to overcome the desynchronization between individual time and intersubjective time. Here two broad strategies might come to mind and might be adopted.

First, one might aim at a direct re-synchronization of the two times involved. In the contemporary literature this has been described as a return to the "virtue of patience" (Fuchs 2001). Here "patience" does not mean that one simply "waits". Instead it means that one feels in accordance - or for that matter: "in resonance" - with one's social environment. The aim is to re-achieve a kind of common rhythm in which to experience the world and the interaction with the people around.

Second, one might aim to overcome the desynchronization between individual time and intersubjective time by trying to escape from the latter time scale altogether. Surely, as soon as I care only about my individual time, there is no way in which I could feel a desynchronization. Usually, however, such an escapism will provide only a shortterm solution to the problem. In daily life one depends very much on other people and, in practice, one might "uncouple" from intersubjective time only occasionally - maybe by doing meditations in which one forgets about the world around one.

From a higher point of view, such a meditative uncoupling might also be viewed as a special case of the first strategy. Successful meditations are often described in terms of an experience of an "eternal now” (cf. also Koch 2010). The experienced present, as it were, widens beyond all limits. That is, within one's individual time there aren't any tensed distinctions left between events being more or less future or past. All is experienced to be ordered in tenseless terms and hence no room is left for any dissonance between subjective and intersubjective (or objective) time.

Various revisionist claims from the history of philosophy hint in a similar direction. Some variant of the idea of an "eternal now" underlies, for instance, Spinoza's claim that (at least "under the dictates of reason") we should ideally be always "affected equally, whether the idea be of a thing future, past, or present” (Spinoza 1992: 4p62). Or think of medieval mysticism and claims such as the following one by Jacob Böhme (1961: 20, my transl.): "He to whom time is like eternity, and eternity is like time, is freed from all strife.” There is no space left for any kind of dissonance or discrepancy because the present as experienced has become all-embracing.

\section{Finitude and Divergence}

A further kind of time-induced or time-related suffering was mentioned at the very beginning of this essay, namely the worry about one's own finitude. This worry might also be described as the "fear of death", and its revisionist overcoming, or at least some kind of adaptation, might be considered, once more, as a central aim of philosophy. Ever since the days of Plato ([18]: 67e) it has been claimed that philosophy is meant to help us in coping with our finitude and with the inescapability of death. Quoting Montaigne (1910: 179): "to philosophize is to learn [how] to die". 
In the light of Sections 3 and 4, this worry about one's finitude might be described as a variant of the desynchronization between intersubjective time and individual time; namely as the fear of an irreversible desynchronization based on the overall stoppage of one's individual time. The coming into existence of ever new and tensedly ordered individual experience supposedly stops, whereas the intersubjective world of all those other people will continue without any serious interruption. (Though this is not the topic of the present paper, it is worth mentioning that there also exists a complementary worry - namely about the stopping of intersubjective time due to dramatic changes in the environment, such as through a nuclear war or severe climate change.)

Thus, in order to explore possible revisionisms, it is important to better understand the internal dynamics of individual time - that is, to better understand the exact processes involved in the formation of experience and of its inescapable presentness. The most fundamental characteristic or ingredient here is the ever new falling-apart or the ever new (tensed) division between what is now and what is just past. Kant (1996) famously described this in terms of what he called the pure form of inner intuition, Husserl (2008) described and analysed it in terms of his concept of a time halo, and L.E.J. Brouwer (1975) termed this ever new divergence of past and present a "two-oneness" and made it the cornerstone of his intuitionistic foundation of mathematics.

Given the limited scope and length of this essay, I cannot go into much detail here (see Sieroka 2015 and 2016 for that). But maybe I can motivate at least some important connotations with the help of the following quote from Feuerbach (1980: 52): "Where there is no time, there is no individual; where there is no individual, there is no experience, and vice versa”. The claim is that, without time, there is nothing which is not divisible; without time, there is nothing in-dividual. Or, to put it the other way round and a little more precisely: where there is something that continuously falls apart something that divides again and again - there is a tensed temporal order. In fact, the German original makes this close relation obvious even on a verbal level, since the German term for "experience" is Empfinden which derives from ent-finden, where the latter means to find oneself to be different, to be distinct, from something. Thus, searching for a single noun describing the experience of a continuous process of fallingapart, once more words such as "di-vergence”, “di-remption”, “di-chotomy” or "divisiveness" might come to mind.

This leads back to the claim from the beginning of Section 3: individual time or time as experienced is fundamentally tensed - and this tensedness is a consequence of the ongoing divergences within this time scale. These scale-internal divergences are not to be confused with the dissonances or discrepancies between different time scales which induce suffering. Instead, these scale-internal divergences provide our encounter with the world with a directedness and it is from here that the talk about an "orientation" or "sense" of an individual life arises. 
Returning to the worry about one's finitude, the last question to address then is that of a possible revisionism. How, if at all, might the fear of death be attenuated? Some comfort might be gained occasionally by the aforementioned part-time escapism of meditation. Further relief could be found in the, again previously mentioned, Spinozist attempt to view all things tenselessly "under the dictates of reason" - that is, to be affected equally, regardless of whether these things are past, present or future.

Before criticising this Spinozist attempt, let me briefly describe a related but milder kind of revisionism - and then turn to a joint criticism afterwards. Instead of suggesting that one should be equally affected by all things, Parfit (1984: 170-184) discusses a kind of pointwise symmetrisation between the past and the future. That is, one would aim to overcome the aforementioned bias towards the future and aim to be equally affected by things which are, say, two weeks past and two weeks future. (Thus, other than the Spinozist attempt, this Parfitian revisionism would still allow for different attitudes towards what is, say, five hours in the future in contrast to what is five years in the future.) Parfit suggests that this would attenuate the fear of death for the following reason: since one does not fear the event of one's birth or the time before, there is then no reason to fear death or being dead.

However, one might object that the latter step in Parfit's argumentation does not necessarily follow. Even if one admits that such a symmetrisation of past and future would be possible, it is not at all clear whether the lack of fearing one's birth will actually override one's fear of death. Why might not the exact opposite happen? Why might not the fear of death override one's easiness with one's origins and thereby lead to an analogous "fear of birth"?

After all, both revisionisms, the Spinozist as well as the Parfitian, make very high demands on human rationality. Even though these revisions may be realizable "under the dictates of reason", it seems questionable whether they will ever occur "under the dictates of immediate experience (or intuition)", as one might call it. Fortunately, this is not bad news, since a full neglect or overcoming of the differences between past, present, and future is not desirable anyway. For this would dampen, if not abandon, experience as such, given that experience itself is fundamentally tensed.

\section{Conclusion}

There are different types of time-induced suffering. First, there is a deceptive one which has nothing to do with time itself but with the use of false metaphors. Then there are different genuine (conceptually related) types of time-induced suffering: stress, impatience, and fear of death. The first two, stress and impatience (and their pathological variants depression and mania), are related to the dissonance or desynchronization between individual time and either intersubjective time or physical time. Such desynchronizations are possible because the different time scales have their individual periodic processes or their particular chains of events which mark their individual "eigenzeit" (their proper or appropriate time scale). Thus, what a 
philosophical revisionism has to seek, in order to avoid stress and impatience, are strategies for re-synchronizing the different processes and time scales involved.

The fear of death might be described as a more specific worry about the stoppage of one's individual time, about there being a termination point in one's continuous and tensed experience of a falling-apart of things (called "divergence" above). To attenuate this, several strategies are on offer. First, based on beliefs about, for instance, metempsychosis or maybe some other religious convictions, one might simply negate the existence of such a stoppage. Second, and less radically, one might aim at the aforementioned kind of short-term transcendence of one's finitude by means of the experience of an "eternal now". Third, there are the aforementioned attempts of turning humans into perfect rational agents which do not distinguish between past, present, and future. And fourth, one might attenuate the upcoming stoppage of one's individual time by fostering and facilitating an ongoing kind of "derivative existence" in intersubjective or physical time - for instance by writing books and articles in order to make one's ideas and thoughts survive or by having children in order to also propagate one's genes.

This is not claimed to be a complete list. The important point is just that, given that human experience qua experience (ent-finden) is fundamentally tensed, there seem to be two general ways in which to attenuate the fear of death: either one has to deny that there is a stoppage of one's individual time (first strategy) or one has to follow a rather indirect or short-term strategy. In the latter case (second to fourth strategy) no full dissociation from the suffering from finitude can be gained ... at least not without giving up one's existence as a conscious individual human being. ${ }^{1}$

1 I would like to thank Jonathan Lorand for his very helpful comments on an earlier draft of this paper. 


\section{References:}

Binswanger, L. (1960): Melancholie und Manie - Phänomenologische Studien. Pfullingen: Neske.

Blumenberg, H. (1986): Lebenszeit und Weltzeit. Frankfurt (Main): Suhrkamp.

Böhme, J. (1961): Sämtliche Schriften, vol. 10. Stuttgart: Frommann.

Bourne, C. (2007): A Future for Presentism. Oxford: Oxford University Press.

Brouwer, L. E. J. (1975): Collected Works, vol. 1. Amsterdam/Oxford: North-Holland.

Feuerbach, L. (1980): Thoughts on Death and Immortality. Transl. J.A. Massey. Berkeley: University of California Press.

Fuchs, T. (2001): “Die Zeitlichkeit des Leidens”, Phänomenologische Forschungen 2001: 59-77.

Fuchs, T. (2013): “Temporality and Psychopathology”, Phenomenology and the Cognitive Sciences 12: 75-104.

Husserl, E. (2008): On the Phenomenology of the Consciousness of Internal Time (1893-1917). Transl. J.B. Brough. Berlin: Springer.

Kant, I. (1996): Critique of Pure Reason. Transl. W.S. Pluhar. Indianapolis: Hackett.

Koch, A. (2010): “Glück und Zeit”, Neue Zeitschrift für Systematische Theologie und Religionsphilosophie 52: 219-231.

Lakoff, G., and Johnson, M. (1980): Metaphors We Live By. Chicago: University of Chicago Press.

McTaggart, J.M.E. (1908): “The Unreality of Time”, Mind 17: 457-474.

Mellor, D.H. (1998): Real Time II. Cambridge: Cambridge University Press.

Montaigne, M. de (1910): Essays., vol. 1. Transl. C. Cotton. New York: Hill 1910.

Nietzsche, F. (1982): “On Truth and Lies in a Nonmoral Sense”. In: The Portable Nietzsche. Ed. and transl. W. Kaufmann. New York: Penguin, pp. 42-46.

Parfit, D. (1984): Reasons and Persons. Oxford: Clarendon Press.

Platon (1977): Phaedo. Transl. G.M.A. Grube. Indianapolis: Hackett.

Renault, E. (2010): “A Critical Theory of Social Suffering”, Critical Horizons 11: 221-241.

Sieroka, N. (2009): "Ist ein Zeithof schon genug? - Neurophänomenologische Überlegungen zum Zeitbewusstsein und zur Rolle des Auditiven”, Philosophia Naturalis 46: 213-249.

Sieroka, N. (2015): Leibniz, Husserl, and the Brain. Basingstoke: Palgrave Macmillan.

Sieroka, N. (2016): “Phänomenale Zeit, Leid und Leidvermeidung - Eine Bestandsaufnahme”, Zeitschrift für philosophische Forschung 70: 47-73.

Spinoza, B. (1992): Ethics. Transl. S. Shirley. Indianapolis: Hackett.

Theunissen, M. (1991): Negative Theologie der Zeit. Frankfurt (Main): Suhrkamp.

This postprint was prepared by Hannah Mahé Crüsemann. 